\title{
LOS VOLCANES DESDE LA MIRADA INFANTIL
}

THE VOLCANOES FROM THE CHILD'S LOOK

\section{Anna M. Fernández Poncela ${ }^{1}$ Sandra E. Huerta Soriano ${ }^{2}$}

\section{Resumen}

El texto es un análisis de la mirada infantil y adolescente sobre los volcanes, el Popocatépetl y la Iztaccíhuatl en Amecameca, una población del estado de México. Se trata de revisar las memorias, representaciones sociales e imaginarios de niños y niñas y jóvenes sobre el tema. Esto se hace a través de un cuestionario donde se solicitan dibujos y frases. Los resultados presentan la mirada de esta joven generación sobre los volcanes y su significado actual.

Palabras clave: volcanes, infancia, representaciones sociales, imaginarios, Amecameca.

\section{Abstract}

The article is an analysis of child and adolescent look about volcanoes, Popocatépetl and Iztaccihuatl in Amecameca, state of Mexico. It is reviewing the memory and imaginary, social representations of children and young people on the subject. This is done through a questionnaire asking drawings and phrases. The results show the look of this young generation about the volcanoes in this time.

Keywords: volcanoes, children, social representations, imaginary, Amecameca.

\footnotetext{
1 Investigadora e docente de la Universidad Autónoma Metropolitana -Unidad Xochimilco, México. Doctora en Antropología cultural por la Universidad de Barcelona. E-mail: fpam1721@correo.xoc.uam.mx 2 Graduada em Antropología pela Universidad Autónoma Metropolitana - UAM. E-mail: fpam1721@correo.xoc.uam.mx
} 
La presencia de los volcanes, el Popocatépetl y la Iztaccíhuatl, es sin lugar a dudas significativa e importante desde muchos puntos de vista, geográfica y simbólicamente, histórica y antropológicamente, arqueológica y ecológicamente, identitaria y socialmente. En torno a los mismos se desarrollan memorias e imaginarios, representaciones y construcciones sociales, las y los artistas amplifican y profundizan su creatividad, la comunidad crea y recrea identidad. Muchos acercamientos interesantes hay sobre el tema, sin embargo, el que desarrollamos con esta investigación se centra en la mirada infantil, cómo perciben, sienten, piensan, qué opinan, cuál es la valoración de niños y niñas que viven en Amecameca sobre los volcanes. La misma se realiza a través de un estudio con infantes de primaria y secundaria, y con dibujos, palabras y frases. Los resultados apuntan hacia una apreciación positiva de los mismos, y su mirada va desde la memoria idealizada y socializada con la leyenda tradicional aprendida en la escuela hasta el temor que introyectan en especial los medios.

\section{INTRODUCCIÓN}

El objetivo de la investigación es recabar, analizar y presentar las representaciones sociales, los imaginarios y las memorias sociales actuales de la infancia de Amecameca sobre los volcanes el Iztaccíhuatl y el Popocatépetl. Sin embargo, y debido a la amplitud de los conceptos en este texto en general nos circunscribiremos a las representaciones, así también los resultados son representativos únicamente del grupo de niños y niñas que participaron dibujando a los volcanes y expresando su testimonio sobre los mismos.

Para cumplir con el objetivo anterior se aplicó un cuestionario en el cual se solicitaba dibujar ambos volcanes e inmediatamente abajo "explicar el dibujo", y que "cuenta algo de los volcanes", esto es, preguntas o mejor dicho indicaciones de carácter abierto y cualitativo. Dicho instrumento fue aplicado a un total de 378 infantes de $4^{\circ}, 5^{\circ}$ y 6 grado de primaria pública y privada, así como los tres niveles de secundaria también en los dos tipos de centro (Véase cuadros muestra).

Este ejercicio tuvo lugar entre los meses de febrero y abril del año 2013 en Amecameca. Amecameca de Juárez es la cabecera municipal (31,000 habitantes) del municipio de Amecameca (31,000 habitantes) en el estado de México que cuenta con unos 48,000 habitantes 
y está situado al oriente del altiplano mexicano (López y Loera, 1996; López López, 1999; Vera Castillo, 2000).

\section{LOS VOLCANES: IMAGEN Y SIGNIFICACIÓN}

Los acercamientos a los volcanes han sido muchos, profundos y diversos, imposibles de enumerar en estas páginas. Desde la pintura hasta la novela, desde la arqueología hasta la antropología, pasando por todas y cada una de las ciencias sociales, sin olvidar las investigaciones de vulcanólogos. No obstante, no queremos dejar de mencionar los estudios pioneros sobre la montaña de Johanna Broda especialmente en los años noventa, el libro entrañable hace poco reeditado de Julio Glockner (2012) y las investigaciones recientes sobre varios temas en torno a las montañas y volcanes en general o en concreto los que aquí trabajamos (Broda, 2009; Loera, 2011; Montero, 2012).

Otras posibles aproximaciones son las que nos inspiran en estas páginas, esto es, el mundo de los imaginarios, las representaciones sociales y las memorias, todo ello a través de las imágenes y discursos de las jóvenes generaciones. Los resultados de esta investigación esbozan las visiones y estimaciones infantiles a cerca de los volcanes, eso sí desde las diferentes etapas del desarrollo infantil (Delval, 1999) y su endoculturación y co construcción social, esto es como parte del imaginario social, las memorias y representaciones de un universo simbólico en el cual se inscriben y pertenecen, entendido éste como matriz de significados socialmente objetivados y aprehendidos como reales (Berger y Luckmann, 1986).

\section{TEORÍA DE LAS REPRESENTACIONES SOCIALES, IMAGINARIOS Y MEMORIAS}

A continuación, definimos brevemente algunos conceptos claves de este trabajo para aclarar de qué estamos hablando, advertir que dada la vastedad e importancia de su significado no los empleamos en profundidad, únicamente a modo de referencia y marco conceptual.

Dicho sucintamente y siguiendo a Cornelius Castoriadis $(1983,1988)$ el imaginario social es una simbolización cultural, que imbrica sentimientos, pensamientos y acciones colectivas e individuales. Lo psíquico y lo social, lo cultural y lo afectivo, se entretejen y conviven. Una urdimbre de significaciones imaginarias que mantiene unida a la sociedad, le da sentido, la dirigen y orientan, "el magma de significaciones imaginarias" como construcción social histórica. 
Por su parte, Sergei Moscovici (1979) considera a las representaciones sociales como interface entre lo psicológico y lo social, lo simbólico y lo real, construcción del conocimiento en la vida cotidiana que comunica y orienta hacia la acción, a modo de red de conceptos e imágenes interactivas evolucionando en el tiempo y el espacio, y retroalimentando reflejo y producción. Una forma de organización psicológica, de comunicación y conocimiento social, que no sólo reproduce, sino que produce, esto es, es un movimiento bidireccional o cíclico entre sujeto y objeto en el acto de conocimiento y comunicación, concepto y percepción son intercambiables (Ibáñez, 1988; Jodelet, 2008). Hay quien habla de construcciones sociales. Las representaciones son representaciones toda vez que construcciones (Van Dijk, 2000) de ese algo concreto en un lugar y tiempo corto y determinado.

Aquí consideramos que cada sociedad y grupo humano conforma sus imaginarios y sus representaciones sociales. Hay quien piensa que las representaciones surgen del lugar intermedio entre el espacio real y el fantasioso, como saber pragmático, conocimiento alimentado tanto por la experiencia como por otros saberes míticos o apegados al mundo real. En este sentido las representaciones combinan experiencias vividas del sentido común y estructuras para la interpretación de la realidad, toda vez que también experiencias míticas en el sentido de imaginarios sociales, significaciones imaginarias para Castoriadis (1988) o imágenes que representan la realidad según Durand (2000,2012). Las representaciones sociales ancladas en el conocimiento común están entre las prácticas y las experiencias conscientes -el sentido funcional en la acción cotidiana- expresando y comunicando, representando algo o a alguien, interpretando, guiando y construyendo el mundo. Los imaginarios emocionales e inconscientes fluyen en imágenes y símbolos que no tienen un fin de comprensión ni de acción sobre un objeto dado incluso pueden no representar nada existente -creencias, tradiciones, costumbres, sueños, mitos, recuerdos- (Durand, 2000).

En resumen, los imaginarios son esquemas de representación, interpretaciones de la realidad, creación social de sentido, que construyen simbólicamente -memoria, experiencia, realidad- desde el origen de lo social, proporcionan identidad profunda y fuerte cohesión al ser entidades culturales amplias de larga duración con un componente mítico, emotivo y movilizador -deseos, proyectos, utopías-. Mientras que las representaciones son representaciones, o en su caso construcciones, de algo -objeto, situación- o de alguien, esto es lo concreto en el aquí y ahora, con espacio y lugar posible, de corta duración, de carácter sociocognitivo, construyen conocimiento con contenido específico sobre la vida cotidiana, saber 
pragmático, lo que piensa la gente y cómo se comunica. Son concretizaciones de los imaginarios de alguna manera o una interfaz entre éstos y la supuesta realidad concreta (Agudo, Astorga y, Banch 2007; Girola, 2012).

A todo esto, hay que añadir la memoria social o colectiva como parte de un imaginario y de unas representaciones sociales del pasado compartidas por un grupo que se movilizan a partir de las necesidades del presente. Representaciones que se ubican en el imaginario social entre la memoria histórica y los recuerdos intersubjetivos, lo que se denomina los marcos socio históricos de la memoria (Halbwachs, 2004). En el caso que nos ocupa se trata de la memoria colectiva en torno a los volcanes; si bien también podría decirse que los volcanes habitan la memoria, en este ir y venir en la configuración de imaginarios sociales, representaciones y construcción histórico social de la memoria, pero y sobre todo la creación y recreación de identidad (Candau, 2001). Así se configuran como en este caso, espacios simbólicos del recuerdo y los lugares de la memoria.

\section{DIBUJOS Y FRASES COMO ESTRATEGIA METOdOLÓgICA DE ESTUdIO DE REPRESENTACIONES INFANTILES}

El trabajar representaciones con niños y niñas y adolescentes es un fenómeno fascinante al observar la expresión y el desarrollo infantil (Delval, 1999). La infancia es una concepción y concepto del siglo XVIII (Aries 1962) que en últimas fechas es valorada en grado sumo (Bajo y Beltrán, 1998). En general su estudio inicia en la psicología -Vigotsky, Piaget, Kohlberg, Connell, Erickson, etc.- pero hoy se abre a otras ciencias sociales. No es posible presentar todos los estudios recientes sobre el tema, sí mencionar que la socialización infantil (Greenstein, 1977) como algo que aquí tratamos, así como la importancia de la misma en el sentido de adquisición de información, sentimientos y creencias para la comprensión, evaluación y relación con el mundo (Fernández Poncela, 2005a, 2005b). Durante el desarrollo infantil se conforma una representación de la sociedad en la que se vive, una representación social determinada sin duda por la población adulta, pero resultado de la actividad constructiva del niño o niña, esto es, en interacción con la realidad social la cual se habita (Delval, 1989).

La socialización infantil -y posterior- como aprendizaje social y adaptación al medio es importante, se interiorizan valores, normas y códigos simbólicos del entorno social y se integran a la personalidad y la conforman. Se trata de la adquisición e interiorización, introyección en su 
caso, de los modos de hacer, actuar, decir, propios de un grupo social, por un individuo. En definitiva, de una construcción colectiva de comportamientos sociales desde el aspecto cognitivo -reglas y conductas-, afectivo -sentimientos y valores- y expresivo -comunicación y significados- (Greenstein, 1977; Piaget, 1986; Friedmann,1997). Es la adquisición -asimilada o introyectada- de conocimientos y experiencias como acerbo subjetivo resultado de la sedimentación de experiencias cotidianas, recetario y tipificación de acciones a seguir, transferencias o internalizaciones de un conocimiento social -intersubjetivo y grupal- en cada individuo (Berger y Luckmann, 1986). Añadir que a la socialización primaria le sigue la secundaria, recalcar la concepción de la socialización desde una posición de reproducción y construcción social de carácter interactivo (Berger y Luckmann, 1986; Delval, 1989).

Por otra parte, el uso de dibujos, palabras y frases como instrumento de recolección de información a la hora de acercarse al sujeto de estudio infantil y aproximarse a sus interpretaciones y expresiones sobre el mundo circundante y sus representaciones mentales internas se ha probado como fructífero y satisfactorio. Una estrategia de captar la visión de la infancia, su comprensión, evaluación y control del mundo social a través de sus medios cognitivos -creencias, opiniones, emociones, actitudes-. Se trata de un acercamiento metodológico indicado y facilitado porque puede hacerse como tarea dentro del espacio escolar, toda vez que se trata de una actividad lúdica que es una forma de expresión de las representaciones sociales y construcciones del mundo, a través de un lenguaje a veces más satisfactorio que el verbal escrito o hablado (Fernández Poncela, 2003a, 2003b, 2007, 2008, 2010, 2011; Siri Podestá, 2002). Aquí se emplea la expresión icónica y lingüística, imágenes y palabras.

\section{REPRESENTACIONES SOCIALES INFANTILES SOBRE LOS VOLCANES EN AMECAMECA HOY. CATEGORÍAS DE ANÁLISIS}

La investigación converge precisamente en las manifestaciones que emanan del discurso -que conforma y conformado a la vez por imágenes, representaciones sociales y memorias colectivas-, en este caso infantil, el cual es nuestra materia prima para la elaboración de un análisis que permita vislumbrar el entramado que emerge de las observaciones de los niños y niñas de la región. 
De tal suerte es necesaria la creación de categorías de análisis que nos permitan el manejo adecuado de la vastedad de la información. Para explicar el proceso de construcción de las categorías de análisis, diremos que:

Una nueva lectura del material codificado sugirió posibilidades de construcción de categorías de análisis, cuyo fin es la interpretación del material, la cual estuvo permanentemente alimentada con la búsqueda de desarrollos teóricos permanentes. (Amuchástegui, 2002).

De ningún modo se pretende escindir o coartar en pequeñas porciones las observaciones recogidas de la investigación, se materializan de este modo con el objetivo de realizar un análisis cuidadoso del universo de información que surgió. Por ello, para fines prácticos del proyecto, es necesario el uso y la construcción de categorías de análisis que permitan el desmantelamiento de los profundos sentires y pensares que la infancia y la adolescencia de Amecameca revelan en todas y cada una de sus observaciones. Dichas categorías son, creemos, las principales representaciones sociales que la infancia amecamequense posee sobre los volcanes, fruto de la memoria colectiva, los imaginarios sociales, esto es, la socialización y construcción social de la realidad.

\section{LOS VOLCANES: DADORES DE AGUA}

En primer lugar, en el discurso infantil se hace patente de manera constante la importancia otorgada al gran elemento natural: el agua, que por excelencia procede de las dos magnánimas fuentes de energía de la localidad: los volcanes.

El agua, un elemento natural, dador de vida, sin agua no hay vida, y en la comunidad de Amecameca, los niños y niñas saben con precisión que sin volcanes no hay agua y por lo tanto no habría vida.

Los volcanes, grandes estructuras geológicas, son ellos participes primordiales en el ciclo del agua; los niños plasman en sus dibujos alegorías que narran la importancia de grandes nevadas en los volcanes que proveen agua a la zona, y dan vida a los cultivos que rodean el lugar.

En temporada de estiaje la comunidad de muy diversos modos, suplica por una nevada en los volcanes, porque de esa manera no faltará el agua en ningún hogar del municipio. Dicha circunstancia es captada perfectamente por las y los niños y lo exteriorizan por medio de sus dibujos. En cada uno de los niveles educativos se aprecia en los breves comentarios la necesidad reiterada de una nevada, de un volcán con nieve, una naturaleza verde, lluvia, 
elementos símbolos característicos que nos manifiestan la imperiosa necesidad de la justipreciada agua.

Los volcanes en la zona oriente del Estado de México son más que una formación geológica, son parte inexorable del modo de vida del amecamequese, en su devenir diario, en su cotidianidad, los volcanes aparecen sin la necesidad de evocarlos, están ahí y es suficiente para que la comunidad tenga agua, al menos la necesaria para su vivir diario. Son un pilar constitutivo de las subjetividades de Amecameca, en muchos sentidos y éste parece ser el primordial.

Los sentidos que otorgan los infantes a los volcanes son muy diversos para cada uno, incluso los volcanes se transforman en seres sexuados, de tal modo que el volcán Iztaccíhuatl es llamado volcana, y la descripción que hacen del volcán se torna en una descripción femenina, es hablar de una mujer dormida, inactiva, en reposo, y bajo la línea de la transmutación de volcán a mujer, se observa en sus diálogos que el volcán dador de agua en realidad es Iztaccíhuatl. Es la madre que amamanta de agua a sus hijos y los protege de los posibles estiajes que pueden sobrevenir. Muy disímil el caso del volcán Popocatépetl, el cual no es observado como el dador de agua, es más bien asimilado como el peligro que puede aquejar a la región -como presentamos más adelante-. Por esta circunstancia los comentarios relacionados al volcán dador de agua, se observan mayoritariamente en la descripción del volcán Iztaccíhuatl.

Para apreciar las observaciones de los infantes, se presentan a continuación solo algunos comentarios de la consigna explica tu dibujo:

"La volcana nos da agua." Mujer, 4o Primaria Pública.

"Este es el Iztaccihuatl, ella está llena de agua." Mujer 6o Primaria Pública. "La Iztaccihuatl es muy grande y tiene agua." Hombre, 4o Primaria Pública.

"Es grande y es bonita y le sale agua." Hombre, 5oPrimaria Pública.

"Los volcanes son algo representativo y el Iztaccíhuatl da agua a Amecameca".

Mujer, 10 Secundaria Particular.

"Los volcanes son lo más bonito, porque sin ellos no viviríamos, sin su agua que viene de los volcanes." Hombre, 3ㅇ Secundaria Pública

Los infantes del nivel educativo primaria, niños y niñas utilizan el lenguaje pictográfico y el uso de la palabra escrita para representar aquellos diálogos familiares donde se aprecian los discursos relacionados al volcán: fuente de agua. La institución familiar y la escolar aportan al parecer información relevante y significativa al entramado infantil que expresa la importancia de la constitución misma del volcán Iztaccíhuatl colmado de agua. El volcán Iztaccihuatl, gigante 
de agua, cubre con su manto líquido a la comunidad de Amecameca, la idea fuerza, la representación social al parecer más importante según este estudio.

\section{AL PIE DE LOS VOLCANES: AMOR Y DESVENTURA}

El ser humano ante la hiperpotencia de la naturaleza, busca respuestas que puedan socorrerle, no busca verdades, necesita certezas, no se cuestiona por la veritas, pretende soluciones que le permitan convivir con esa naturaleza divina; se responde a través de medios mitológicos y crea imaginarios. La cosmogonía de cada espacio y tiempo, posee sus propias historias, sus mitos, sus leyendas, etcétera, las cuales cumplieron en su momento, con el propósito de encarar el rostro mitológico del mundo y la humanidad. Por rostro mitológico se hace referencia al orden de lo espiritual, la dimensión impalpable, incuestionable, intocable, inmaculada de toda sociedad, si bien puede ser respondida con ciencia, religión o arte, es muy posible que la contestación intangible sea también espiritual, y la leyenda emerja como instrumento mágico-religioso que dé pauta a la solución de las problemáticas de la naturaleza divina (García Gual, 1999).

Si la palabra mito deviene en ficción es un asunto sumamente griego- europeo. Para poder pensar el mito en México es trascendental pensar en el mito vivo, vivir el mito, el mito vivido como real y verdadero (Eliade, 2001), situación que esclarece el origen sobrenatural del mundo y del hombre; historias y leyendas que responden a hechos reales de la naturaleza misma.

Amecameca, sociedad con un propio rostro espiritual y divino, vive sus mitos, los recrea y los fortalece por medio de la institución familiar, la institución escolar o la institución religiosa, mitos que no tienen un autor/a, anónimos que convergen con la autoría social del lugar mismo, que hace prevalecer o perecer actos propios de la leyenda, fabricaciones, resultado de la memoria colectiva y proyectados en el imaginario y aterrizados en representaciones sociales.

Las producciones de la memoria colectiva, son provistas por la comunidad y para la comunidad, pues es en la comunidad misma donde se originan. En Amecameca, adultos, ancianos, jóvenes e infantes son integrantes en movimiento de una sociedad viva y real, que participan de esos mitos y que explica de manera extraordinaria el origen de sus espléndidos gigantes: Iztaccíhuatl y Popocatépetl. 
Las miradas de la población infantil y adolescente hacia los volcanes, están íntimamente ligadas y atravesadas por una historia de amor, poética-romántica, que de algún modo viene a constituir modos de ser, de estar, de convivir, incluso pudiese pensarse en la tarea de construir géneros, o bien, de reafirmar las posibilidades de acción para uno u otro género, nos referimos con prontitud a la leyenda de los volcanes.

Es la herencia de un amor puro y no consumado, actitudes masculinas y femeninas que nos son dadas como naturales. Paralelamente a una explicación de género, aparece la posibilidad de la respuesta a la interrogante por excelencia, casi ontológica, el origen de los volcanes. Más sublime que eso, no existe.

Es inherente al pensamiento, pensar en los volcanes es pensar en la leyenda, leyenda que en sus orígenes era transmitida de padres a hijos, manteniendo la tradición oral entre los habitantes. Ante el cuestionamiento y el asombro, surge la inquietud y la innata curiosidad por saber si la leyenda es real, si el guerrero y la princesa existieron, si en realidad los volcanes se formaron a partir de la tragedia mexica, o si es el medio que permite a la misma comunidad responderse ante tal hallazgo: salir y ver la majestuosidad de los gigantes de hielo, ahí ante su mirada, se convencen de la veracidad de la leyenda de amor y desventura que, además, satisface enteramente sus cuestionamientos.

Las observaciones infantiles y adolescentes no escapan de la mitología es más la ensalzan, sus comentarios están envueltos en una historia, si no es exacta, es muy aproximada, con actos y escenas de la leyenda que cumple su cometido, y engalana el discurso atravesándolo hasta el inconsciente mismo de Amecameca.

La leyenda, hoy por hoy, no es transmitida de padres a hijos, la tradición oral se encuentra gravemente en extinción, casos aislados permiten apreciar la decadente tradición oral, los infantes argumentan que la leyenda les fue transmitida en la institución escolar, la historia romántica aparece en el libro de historia de la SEP de segundo grado de primaria, de tal modo, ellos tuvieron así su primer acercamiento con la leyenda, núcleo fundamental de la memoria colectiva del municipio.

Aquí breves comentarios recogidos de los dibujos, en el apartado cuenta algo sobre los volcanes:

“...Era un guerrero y una princesa, pero en ese momento se desarrolló una guerra, además el padre de la princesa nunca estuvo de acuerdo así que la engañó diciéndole que murió el guerrero que amaba, ella muere 
de tristeza, cuando llega el guerrero le dicen que ha muerto su amada, así que se va, se la lleva y así nacen las dos grandes montañas..."

Mujer, 6o Primaria Particular.

"Dice la leyenda que Iztaccíhuatl era una princesa que se enamoró de Popocatépetl un guerrero. Su padre le dijo que le daría la mano de su hija si volvía victorioso de la guerra, entonces un día un mensajero llegó con una nota que decía que Popocatépetl había muerto, ella tan triste cayó en un profundo sueño del cual nunca despertó, él la llevó a la cima de la montaña y se quedó con ella." Mujer, 10 Secundaria Particular.

"Eran dos enamorados y que el papá de ella no los dejaba ser feliz, y después ella muere y su amado la entierra y se queda con ella por el resto de la vida."

Mujer, 2o Secundaria Pública.

Para la comunidad de Amecameca la leyenda vive, es auténtica y real, por lo menos en los imaginarios de niñas y niños.

En el caso específico de la etapa del desarrollo humano adolescente resulta ser más que un cuento mítico o una historia de amor, sus reflexiones son más profundas de lo que podemos imaginar. Las jóvenes de secundaria, al plasmar en sus dibujos y sus diálogos la leyenda de los volcanes, hacen un análisis muy interesante del modo en que la leyenda las atraviesa y como ellas la manifiestan en su devenir cotidiano. La leyenda como instrumento para la construcción de género, herramienta privilegiada por medio de la cual se reproducen concepciones tradicionales y estereotipadas respecto a los modos de ser hombre y mujer, son el resultado de la convivencia permanente con la introyección de esta historia viva (Fernández Poncela, 2000, 2002a, 2002b).

Las expresiones surgidas en el análisis de las adolescentes, giran en torno a las formas de comportamiento de cada uno de los personajes de la leyenda, sobre todo en el personaje de Iztaccíhuatl, circunstancia que enriquece y esclarece en la fabricación de prácticas sociales cotidianas en el municipio de Amecameca.

La princesa Iztaccíhuatl encarna la representación social del comportamiento femenino. El dilema histórico de obedecer la ley del padre; de esperar pacientemente el idilio de amor y sucumbir ante la posibilidad de la separación eterna del ser amado; pensar que el hombre que las ame, estará con ellas en cualquier situación que sobrevenga y que ni el escenario más funesto (la muerte) podrá separarlas del amor genuino.

Las adolescentes después de realizar sus dibujos y sus comentarios, expresaron su parecido personal con el personaje de Iztaccíhuatl, argumentando que sus padres en la vida real no les permiten tener novio como el papá de Iztaccíhuatl, y que como a ellas, su padre tampoco 
le dio autorización para relacionarse con Popocatépetl, de un modo similar han pensado en revelarse contra la voluntad de su padre, no con un suicidio pero sí con escaparse con su novio o con mantener una relación oculta.

Algunas jovencitas, expresan también su deseo de encontrar a una pareja que las ame incondicionalmente y que las acompañe toda la vida, las proteja y vele por su amor, el cual tendrá posteridad después de la muerte también.

Los adolescentes por su parte, no manifestaron la misma lectura de análisis que las adolescentes; las expresiones de sus dibujos y escritos son de diversa lectura. Sus dibujos se relacionan con escenarios pre-apocalípticos respecto al comportamiento geológico del volcán Popocatépetl. Ellos

relatan también la leyenda de los volcanes, pero con menos detalles, la generalidad indica una historia lineal y sin matices, se observa una inclinación afianzada por los dibujos de erupciones volcánicas y un relato breve de la leyenda de los volcanes. Es interesante resaltar el conglomerado de una imagen terrorífica de una erupción volcánica a la par de un relato concreto de la historia romántica de los volcanes.

"La historia de los volcanes no me gusta." Hombre, 1올 Secundaria Pública

"La leyenda cuenta que era una mujer que amaba a un guerrero, pero su padre para aceptar la relación le pidió que fuera a la guerra, después le dijeron a la mujer que él había muerto y ella se mató por la tristeza porque supuestamente el hombre que amaba se murió."

Hombre, 1은 Secundaria Pública.

Si bien los adolescentes expresan con dificultad sus sentimientos en relación con la leyenda de los volcanes, tampoco niegan la existencia de la misma, emerge de sus estructuras psíquicas una historia que da origen al nacimiento de los volcanes y la edificación de prácticas sociales que atraviesan la conciencia masculina de los adolescentes. Ser fuertes y valerosos para ser dignos de la mujer amada, no es necesaria la participación en la guerra, basta con ser el sujeto idóneo para pretender a la sucedánea y obtener triunfantes el permiso del padre de la novia para enamorarla y relacionarse con ella.

La leyenda como instrumento de reproducción de estereotipos se observa reiterativamente en las adolescentes, una suerte de introyección-proyección, ellas lo asumen personalmente y lo reproducen en su vida cotidiana. La leyenda les permite pensar en la posibilidad de erigir un medio por el cual la fantasía se puede convertir en una realidad contundente. Si su vida no trasciende en el origen de un nuevo volcán, sí pueden eventualmente imaginar un parecido extraordinario con la historia poética de la leyenda de los 
volcanes en relación con su experiencia personal. Los volcanes no solo tienen género (Iwaniszewski, 2001) y se humanizan y conciben y representan como seres humanos, se aparecen o se imaginan, las y los jóvenes de Amecameca se proyectan en ellos y ser resuelven a través de sus vivencias en los relatos legendarios y personajes a través del ejercicio propuesto por la investigación.

\section{LOS VOLCANES: UN PELIGRO PARA AMECA}

Desde la actividad volcánica de 1994, los/as habitantes de Amecameca han permanecido en una situación de alerta, en particular la preocupación oscilante respecto al volcán Popocatépetl. De ser divinidades resultan ser bombas de tiempo: peligro inminente.

El estado de alerta, en realidad se manifiesta de manera reciente, los sonidos nocturnos originados en el cráter del volcán, atemorizan de vez en cuando a la población, sonidos que según nuestros abuelos han acompañado desde siempre al municipio, y en palabras cotidianas de sus discursos "nunca ha pasado nada".

Las generaciones de hoy, tienen una concepción muy distinta a la de los abuelos/as, la actitud de las y los residentes resulta confusa, la cotidianidad hace que la situación del volcán parezca mermada y a la vez atemorizante, les parece un tema de relevancia social absoluta.

El posicionamiento de los padres con respecto al volcán es transmitido a los hijos, de tal modo que la infancia de Amecameca expresa claramente su miedo al volcán Popocatépetl. Los temores son diversos. Temen perder su casa, su familia, su vida como la conciben, a morir, y no saben qué hacer si una erupción volcánica sobreviene a su comunidad. Al parecer no tienen un plan familiar de protección civil en caso de erupción volcánica. Se sienten desprotegidos y desorientados, no sabrían qué hacer. Lo cual aparece como una clara representación social de temor y un imaginario de peligro que se observa en la infancia.

Los dibujos expresan un volcán en erupción, con lava, fumarolas, piedras, en destrucción total. Puede pensarse en la posibilidad de una erupción lejos de su hogar debido a que el volcán está solo, solitario con su erupción, nadie merodeando, lo cierto es que le temen porque aparece en conjunto con sus comentarios que hablan de peligro y de un miedo intenso al volcán Popocatépetl. Eso sí, un volcán con las características de los de Hawai que poco tienen que ver con nuestras montañas sagradas símbolo del país. 
Se presta a distintas lecturas, la multirreferencialidad del discurso (Ardoino, 1988), pretende un abanico de opciones para analizar las miradas infantiles de Amecameca. En un primer vistazo se observan dos entes sexuados, el volcán y la volcana, el padre y la madre. La madre que atiende a sus hijos y los abastece de agua, la madre pacífica, amorosa, adormilada, que vigila a sus descendientes desde el sueño profundo; y al volcán Popocatépetl, molesto, furioso, es el padre que otorga la ley, que disciplina a sus hijos, que se hace respetar por ellos, que les recuerda en todo momento que existe, que es real y que si cometen faltas los tendrá que disciplinar. Una erupción volcánica equivaldría a una muy buena llamada de atención del padre a su hijo. No es una furia cegada, es una reprimenda con un propósito, sus hijos deben aprender la lección. Los dibujos materializan a un volcán Popocatépetl que infunde respeto y temor.

Por el lado poético-romántico, literario, ese amor platónico que no pudo ser. Un amante enardecido porque su amada ha caído en un sueño sin retorno, molesto, furioso en plena erupción, ermitaño, sin compañía más que la de su adorada dama dormida. Ella en posición de descanso, boca arriba, sin posibilidad de volver a la vida, en reposo, dibujada en actitud pacífica. Él vivo y ella muerta. Vivo y con aparente furia destructora a través de los tiempos.

Desde otro ángulo. Si los abuelos vivieron con absoluta tranquilidad y equilibrio con los volcanes, ¿̇a qué se debe el cambio de pensamiento en las generaciones actuales respecto a los volcanes? De ser un ente divino ahora es un posible desastre. Los dibujos y los comentarios infantiles no permiten leer de manera literal las razones de dichos cambios, sin embargo, los dibujos y lo que sí se puede leer entre líneas son las expresiones hollywoodenses de erupciones ajenas a las erupciones del volcán Popocatépetl. Las erupciones más violentas que se han presentado en fechas recientes no han sido catastróficas como para considerar a Amecameca zona de desastre. Son erupciones que a veces incluso pueden ser gozadas por la misma población, es la admiración de un espectáculo natural que nunca se va a volver a repetir, y a que no serán igual a las erupciones futuras. Es la energía que expulsa la tierra para su propio reequilibrio.

Los medios de comunicación tienen un papel protagónico en esta tragicomedia, porque la información que eligen y constantemente transmiten por radio y sobre todo por televisión, se encuentra claramente manipulada, explotada y exagerada, seguramente por la venta de las 
notas; no consideran daños o consecuencias colaterales, es preciso inventar, impresionar y vender a cualquier costo, una manera actual de sentirse vivos.

Algunos pobladores han comprobado por sí mismos la manipulación mediática, de una fumarola que no representa peligro alguno hacen en la televisión toda una serie de intrincados sucesos fatales que podrían acabar con la humanidad en cuestión de minutos, se descontextualizan imágenes y se exageran comentarios.

La subjetividad infantil está sumergida en un mar de subterfugios confusos, difíciles de discernir, los adultos están imposibilitados para analizar lo que se mira por televisión; bajo la premisa de que "la televisión tiene la razón", es complicado poder mirar con otros ojos a nuestros gigantes del Valle de México. La infancia escucha a sus padres, ve la televisión, noticias y películas de volcanes.

Somos la nueva generación, la in-volución: los Homo Videns. La vista no piensa, solo transmite, no podemos pensar lo que tenemos frente a nuestras narices, solo podemos ver y transmitir. Nuestro pensamiento simbólico es atrofiado por la imagen funesta de la televisión (Sartori, 2006) que opaca la memoria antigua, el sentimiento identitario y el imaginario tradicional y popular de otros tiempos.

A continuación, breves comentarios sobre el volcán Popocatépetl:

"El Popocatépetl es el hombre que tira lava. Es peligroso porque puede explotar y cae lava roja y muy lenta baja la lava." Mujer, 4o Primaria Particular.

"El Popocatépetl está explotando, y saca piedras y mucho humo." Mujer, 40 Primaria Particular.

“El Popocatépetl haciendo erupción que mata a todos." Hombre, 5 은 Primaria Particular.

"El Popocatépetl está enojado echando erupción." Mujer, 5o Primaria Particular.

"El volcán explota, y caen piedras." Mujer, 50 Primaria Pública.

"Los volcanes sirven para traer agua al municipio, pero pueden ser muy peligrosos."

Hombre, 1을 Secundaria Pública

"Hacen erupción y me espantan." Mujer, 1o Secundaria Pública.

"Los volcanes me dan miedo y tienen nieve." Hombre, 1ㅇ Secundaria Pública

Los comentarios al respecto son variados, el temor latente y explícito a una erupción volcánica es visible en niños y niñas. Las que expresan con claridad el miedo a un desastre natural son las niñas, ellas manifiestan sus emociones agobiantes por medio del uso de la palabra. Por el contrario, en los dibujos se representan la tendencia marcada de los niños, son 
quienes dibujan con frecuencia al volcán haciendo erupción, con lava, con piedras, con una fumarola y solo en algunos discursos se aprecia la emoción del miedo en forma de brevísimas palabras. Otra cuestión genérica a tener presente: ellas hablan de su miedo, ellos lo plasman visualmente.

\section{LOS VOLCANES: UN LUGAR PARA DESCANSAR}

La capacidad de imaginar un lugar ideal para descansar es un ejercicio mental que resulta muy tranquilizador y colmado de paz para quien lo realiza. Las observaciones vertidas por algunos infantes del municipio dio como resultado la sugerencia de utilizar responsablemente los parques aledaños a los volcanes como preciosos lugares para el descanso, convivencia y la relajación.

Según algunas miradas los volcanes representan temor, miedo, amor, romanticismo, fuente de vida, y hay quienes consideran también la posibilidad de mejorar sus medios de subsistencia y condición económica a través del turismo, y el uso adecuado de los hermosísimos paisajes de los volcanes. El aumento de turismo en la zona, aumentaría los ingresos de los habitantes de Amecameca. Las personas no tendrían que buscar empleo fuera de su ciudad de origen, podrían trabajar cerca de su hogar, y cuidarían de los alrededores de su comunidad.

Breves comentarios sobre los volcanes como un lugar turístico:

"A mí me gusta cuando neva el Popo porque voy con mi familia a divertirme."

Mujer, 4o Primaria Pública.

"Cuando los volcanes tienen nieve, más gente viene y llegan los turistas." Hombre, 5o Primaria Pública.

"Los volcanes atraen a mucha gente" Hombre, 5o Primaria Particular.

"Los volcanes son una maravilla de aquí, en Amecameca, deberían visitarlos."

Mujer, 6o Primaria Pública.

"Los volcanes son nuestra joya es lo que atrae al turismo, más cuando están nevados."

Mujer, 1을 Secundaria Pública.

"Estos son turísticos porque muchas personas los vienen a ver" Mujer, 1 - Secundaria Particular.

"Pues son muy bonitos los volcanes, hablan muy bien de nuestro municipio, ya que los tenemos a ellos." Mujer, 2o Secundaria Pública.

"Los volcanes son una atracción turística para todos, ya que son un bonito paisaje en México."

Mujer, 3 ㅇ Secundaria Particular. 
La invitación explícita infantil para visitar y conocer los volcanes es una propuesta que surge de la experiencia personal de conocerlos, y del saber que existen momentos adecuados para subir a ellos. En los comentarios se aprecian los escenarios nevados como posibles circunstancias que hacen atractivo el paseo.

Geográficamente, Amecameca se ubica en las faldas de los volcanes, a 20 kilómetros en línea recta del volcán Popocatépetl, es una distancia relativamente corta, distancia que puede ser recorrida por los habitantes de la comunidad y por supuesto por los turistas que gustan de la montaña y la naturaleza.

De manera muy atinada los niños y niñas de Amecameca, observan con claridad al municipio de Amecameca como un lugar turístico ideal para conocer y descubrir las maravillas que guardan cada una de las veredas que conducen a los volcanes. "Los volcanes son bonitos y es lo que hace a Amecameca un lugar turístico". - Mujer, 6o Primaria Particular.

La reciente actividad volcánica, lejos de extinguir el comercio y el turismo en los parajes de la montaña, ha dado paso a la creciente proliferación de distintos espacios turísticos en los alrededores del Parque Izta-Popo Zoquiapan, los cuales cuentan con diversas actividades recreativas como el uso de cuatrimotos, montura de caballos, comida, caminatas por las veredas, toma de fotografías en ríos y cascadas, renta de cabañas, y la posibilidad de acampar en áreas selectas destinadas a dicha actividad.

La posibilidad de concentrar un mayor número de turistas en la región, resulta ser una propuesta muy seductora para la comunidad, sin embargo es importante contemplar la propuesta en un proyecto sustentable que albergue las necesidades económicas del lugar, que permita el desarrollo de oportunidades para todos los ciudadanos considerando el aspecto social del municipio y que la generación actual por medio del proyecto sustentable cuida y proteja los ecosistemas para que las generaciones venideras puedan gozar de los beneficios de los nichos ecológicos, y den pauta para la conservación permanente del medio ambiente.

\section{LOS VOLCANES: IDENTIDAD Y ORGULLO AMECAMEQUENSE}

La existencia de interrogantes ontológicas en el ser humano son el resultado de una serie de reflexiones y análisis que procuran la resolución de misterios acumulativos en el universo, en su contexto, en su sociedad. La incógnita histórica de saber acerca del origen de la comunidad despierta intereses de distinta índole, teniendo el común denominador de la 
búsqueda de una identidad colectiva. Pensar y sentir que Amecameca mantiene una relación intrínseca con los volcanes puede resultar una columna muy significativa edificada en lo más recóndito de la memoria colectiva.

Más allá de enunciar la identidad de Amecameca en una mera descripción de sus rasgos étnicos-culturales que puedan discernir de otras comunidades, o incluso basarnos en una específica ubicación geográfica del espacio, que sin lugar a dudas le da connotación singular a la comunidad misma, se pretende a partir del discurso infantil analizar la identidad de Amecameca con los elementos pictográficos, escritos y verbales que la infancia expresó en el instrumento de análisis que se les aplicó.

El hecho de vivir en un espacio en el que convergen naturaleza, volcanes, provincia, tranquilidad, urbanidad y un ambiente pacífico y noble, hace de Amecameca un lugar idóneo para vivir y del cual sentirse orgulloso. Un paisaje natural y un territorio cultural que desarrolla el apego, conmueve y es símbolo de pertenencia y vivencia.

Cabe aclarar que las manifestaciones artísticas de los niños de Amecameca en realidad expresan su deseo de sentirse orgullosos de los volcanes. La apropiación cuasi natural que emana de ellos parece ser otorgada por una especie de permiso que accede a la posibilidad magnificente de decir: $\underline{\text { mis volcanes, }}$ eso es justamente lo que la infancia articula en sus creaciones.

Comentarios acerca de la identidad que generan en la comunidad de Amecameca:

"Los volcanes son grandes colosos que representan a Amecameca." Hombre, 2ㅇ Secundaria Particular.

"Mis volcanes son un centro turístico que enorgullecen a Amecameca." Mujer, 3 o Secundaria Particular.

"Los volcanes son parte de una leyenda, pero lo más importante es que me hacen estar orgullosa porque son de las pocas ciudades que logran apreciar su belleza."

Mujer, 3ㅇ Secundaria Pública.

"Pienso que son muy bonitos ya que es un atractivo de Amecameca, y que es un orgullo porque tenemos mucha riqueza natural." Mujer, 3o Secundaria Pública.

La identidad reflejada en los diálogos de las niñas y de los niños manifiesta una identidad cargada de valores, no basta con realizar una descripción para definirla, se refiere a una identidad de una representación que tiene el sujeto de sí mismo (Villoro, 1998).

La identidad de Amecameca está presente y se puede palmar por medio de sus formas de sentir, de vivir, de cohabitar en una relación espiritual-cultural con los volcanes. La tranquilidad que genera tener una identidad comunitaria, solo es posible gracias a la necesidad 
imperiosa de tener una identidad. La leyenda de los volcanes que cumple una función psicosocial se incorpora de forma magistral para crear la tan anhelada identidad amecamequense. La historia obnubilada de las culturas mesoamericanas no permite el análisis extendido de los primeros pobladores de la región Izta-Popo, los fragmentados rescatados que por sus condiciones son de carácter interpretativo, solo dan cuenta de una pequeñísima porción del entramado cultural y social de lo que fue Amaquemecan.

La relación que mantiene Amecameca con los volcanes se sabe histórica a pesar de las vicisitudes del tiempo y espacio se conserva y vive en los habitantes, una relación identitaria. Eso se observa hasta la generación más joven como hemos dejado patente en estas páginas. Los volcanes son parte de Amecameca y Amecameca es parte de los volcanes.

\section{CONCLUSIONES}

Así, la familia y la sociedad en su conjunto, maestros y maestras o lecturas escolares nos van conformando como seres sociales. El discurso escolar y los libros de texto, como parte del discurso hegemónico cultural transmite e introyecta una serie de mensajes que tienen que ver con lo establecido en cada contexto socio histórico. Niños, niñas, adolescentes y jóvenes incorporan, a través de la endoculturación, consciente o inconscientemente, de forma activa y dinámica, ideas y prácticas sociales que se relacionan tanto con su visión del mundo y de la vida, además de ser instrumentos de su propia construcción identitaria personal y especialmente social. A la endoculturación de la educación formal, se suma la de la familia, y la de los medios de comunicación, esta última de gran impacto en nuestros días, como se ha señalado en su momento.

La conformación de la identidad del yo (psicosocial) y del nosotros (colectiva o social) pasa por la familia, la comunidad, la tribu, el lugar de nacimiento, la clase social, el grupo étnico y la nacionalidad (Elias, 1990). Porque somos lo que hacemos, y a través de la construcción de la identidad del yo lo que se busca es construir y reconstruir un sentido de identidad coherente (Giddens, 1997). Dicho sentido se aprecia en la infancia y adolescencia amecamequense.

Las miradas infantiles sobre los volcanes parten de un imaginario abstracto y de larga data y de unas representaciones concretas y prácticas -creencias, prácticas, concepciones, anhelos colectivos y valores sociales que dan coherencia a un grupo social determinado-, así como de una memoria histórica preñada de recuerdos intersubjetivos y colectivos -atravesados 
a su vez por leyendas, discurso escolar, relatos familiares e información en los medios-. Una suerte de registro subjetivo coherente, pero también dinámico y cambiante, individual y colectivo, como auto concepción grupal. A modo de una institución de la sociedad, institución de significaciones imaginarias sociales que dan sentido (Castoriadis, 1983, 1988). Toda vez que es una representación social, entendida ésta como producción mental colectiva que va más allá de las personas como individuos y conforma el bagaje cultural de una sociedad (Ibáñez 1988).

El análisis realizado a las solicitudes pictóricas y expresiones verbales escritas (dibujos y frases) nos da cuenta de un paisaje social, emocional y cultural, psicológico e identitario, ritual y simbólico, pero y también material y experiencial, que se introyecta y proyecta, que se piensa y se siente, que se vive y representa y revive.

1-Los volcanes fueron, son y serán dadores de vida a través del agua, agua para el cultivo, agua para la población y sus viviendas, en fin, agua para la vida. Y es que agua, tierra, aire y fuego se dan cita en el paisaje amecamequense y se observa en los dibujos como los cuatro elementos se esbozan y entrelazan. Pero volviendo al agua la categoría y discurso prevaleciente según nuestro análisis es una representación social clara y persistente relacionada íntima e intrínsecamente con la existencia misma y que pervive ligada al imaginario y memoria ancestral sobre el tema.

2-Los volcanes personificados y proyectados como seres humanos en la leyenda, no solo son protagonistas de una importante historia de amor, sino que son fuente de identificación genérica, hombres y mujeres se identifican con los seres legendarios, reproducen estereotipos y roles de género (Fernández Poncela, 2002a, 2002b), toda vez que expresan sus anhelos vivenciales personales en un ir y venir entre los personajes y sus vidas, reflexionan sobre sus propias relaciones amorosas y paternales. Imaginarios y memorias se entrelazan, no sabemos bien sólo podemos intuir el profundo significado de sabiduría que como toda leyenda esta narración encierra y transmite a quienes pueden y quieren descifrarla; sin embargo, sí podemos observar su función psicológica genérica para la interpretación en nuestros días, reproductora aparente de del discurso hegemónico actual de los roles sexuales y los estereotipos sociales. Pero más allá de las representaciones sociales o en paralelo a las mismas se introspecta y tal vez se suelta tensión con el sólo hecho de la identificación, reflexión y expresión personal de la narración.

3-Los volcanes y la representación social transmitida constantemente de forma exagerada y alarmista por los medios como un peligro, en vez de considerarlos solo una 
posibilidad de riesgo -relacionado como todo riesgo con la gestión de la vulnerabilidad-, aparece también en las jóvenes generaciones. Aquí el análisis de género surge nuevamente y se refleja el peligro y temor en las palabras de ellas y el peligro con menos temor en los dibujos de ellos. También hay que mencionar para este caso las diferencias generacionales, el temor se transmite al parecer por los medios a los padres e hijos/as, mientras las personas de mayor edad parecen ser parte de otra mirada sobre el tema y presentan una visión atenuada sobre la posibilidad de una contingencia, premia la convivencia y relación con la tierra, no el miedo ante la misma. Memoria de una relación amorosa que permanece en los viejitos y viejitas -según entrevistas realizadas-, mientras que el imaginario mediático y de confrontación aparece entre las generaciones más jóvenes con la endoculturación mediática.

4-Los volcanes, representación social de esparcimiento, ocio y descanso según la infancia y adolescencia, se entreteje con los escenarios e imaginarios del turismo en la región y su posibilidad de crecimiento con el consecuente incremento de fuentes de empleo y subsistencia garantizada. Al respecto hay que tener en cuenta la historia de los cambios en la materia tras las erupciones de 1994 y la prohibición de la subida al volcán que ocasionó la disminución de visitantes, así como el nombramiento reciente de Amecameca de Pueblo con Encanto por el gobierno del estado y la posibilidad de incremento de turistas. Esta mirada parece clara en la infancia como propuesta de futuro.

5-Los volcanes son finalmente -pero no menos importante- fuente de orgullo e identidad, donde memoria, imaginarios y representaciones sociales convergen en el paisaje natural y cultural, emocional y simbólico, social y físico. "Mis volcanes" como algunos dicen y es que desde Amecameca el paisaje es más que imponente, es parte de la cultura y la existencia, y como se dijo con anterioridad los volcanes y la ciudad no pueden pensase ni entenderse unos sin la otra y viceversa.

En todo caso los volcanes están significativamente presentes en las miradas de niñas, niños y adolescentes analizadas -si bien reconocemos que provocamos activamente el reconocimiento a través de la aplicación del ejercicio aquí presentado, una injerencia metodológica necesaria- son parte de su bagaje paisajístico real cotidiano, de su experiencia de vida y de su cultura circundante, son imagen y discurso, son memoria e identidad, imaginario y representación social. Pero hay que ver su significado profundo y más allá de la representación de peligro y la sensación de miedo, sobresale en general una emocionalidad vinculante con la 
naturaleza, el agua, la tierra, el aire y el fuego, socialmente identitaria, relacionada con el recreo y concebida desde el amor.

\section{BIBLIOGRAFÍA}

AMUCHÁSTEGUI, Ana. El significado de la virginidad y la iniciación sexual. Un relato de investigación. Para comprender la subjetividad. Investigación cualitativa en salud reproductiva y sexualidad. D.F., COLMEX, 2002.

ARDONIO, Jacques. Conferencia dictada el día 21 de noviembre de 1988, en la Universidad Autónoma Metropolitana-Xochimilco. Transcripción de Alejandra García, David Paredes y Alma Luz Martínez. Traducción Roberto Manero, D.F. UAM-X, 1998.

BAZ, Margarita. Singularidad y vínculo colectivo. Consideraciones Metodológicas en Anuario de Investigación del Depto. de Educación y Comunicación. D.F, UAM -X, 2000.

BECK, Ulrich y BECK-GERNSHEIM, E. La individualización. El individualismo institucionalizado y sus consecuencias sociales y políticas. Barcelona, Paidós, 2003.

BERGER, Peter y LUCKMANN, Thomas. La construcción social de la realidad. Buenos Aires, Amorrortu, 1986.

BAJO, Fe y BELTRÁN, José Luis. Breve historia de la infancia. Madrid, Temas de hoy, 1998.

BANCHS, María A.; Álvaro Agudo Guevara y Lislie Astorga. Imaginarios, representaciones y memoria social en Arruba, Ángela y Martha de Alba (Coords.) Espacios imaginarios y representaciones sociales. Aportes desde Latinoamérica. Barcelona, Anthropos/UAM-I, 2007.

BRODA, Johanna, Satanislaw Iwaniszewski y Arturo Montero (Coords.) La montaña en el paisaje ritual. D.F, UNAM-IIH/ENAH-INAH/CONACULTA, 2001.

CANDAU, Jöel. Memoria e identidad. D.F, Ediciones del sol, 2001.

CASTORIADIS, Cornelius. La institución imaginaria de la sociedad, Barcelona, Tusquets, 1983. Los dominios del hombre: las encrucijadas del laberinto, Barcelona, Gedisa, 1988.

DELVAL, Juan. La representación infantil del mundo social en Turiel, Elliot; Enesco, Ileana; Linaza, Josetxu. El mundo social en la mente infantil. Madrid, Alianza Editorial, 1989.

El desarrollo humano. Madrid, Siglo XXI de España Editores, 1999

DURAND, Gilbert. Lo imaginario. Barcelona: Ediciones del Bronce, 2000. Las estructuras antropológicas del imaginario. México: FCE, 2012.

Fernández Poncela, Anna María. Protagonismo femenino en cuentos y leyendas de México y Centroamérica. Madrid, Narcea, 2000. 
Pero vas a estar muy triste y así te vas a quedar. Construcciones de género en la canción popular mexicana. México, INAH, 2002a.

Estereotipos y roles de género en el refranero popular. Charlatanas, mentirosas, malvadas y peligrosas, maltratadores, machos y cornudos. Barcelona, Anthropos, 2002b. 2003a.

El presidente Fox en el imaginario infantil y juvenil en Política y cultura, $n^{\circ} 19$, D.F., UAM/X,

De la Llorona al presidente Fox: la percepción infantil y juvenil sobre la construcción nacional y de género Cuadernos Americanos, n99, D.F., UNAM. 2003b.

Infancia, adolescencia y política. México: Miguel Ángel Porrúa/IEDF. 2005a .

Canción infantil: discurso y mensajes. Barcelona, Anthropos, 2005b.

Elecciones, campañas, partidos y candidatos: el 2 de julio de 2006 desde la mirada infantil en Veredas, n¹4, D.F., UAM/X, 2007.

Dibujos y frases de la infancia: una mirada hacia los candidatos presidenciales en 2006 en Revista de Estudios Electorales, n7, SOMEE, México, 2008. 2010

Nacionalismo e infancia: cambios y permanencias" en Convergencia, $n^{\circ} 52$, D.F., UAEM,

Capital social y participación política en las jóvenes generaciones en Luís Reyes García, Claudia Alaniz Hernández y Miguel Ángel Olivo Pérez (Coords.) Docencia, identidades, organización y cultura escolar. D.F., UPN, 2011.

FRIEDMANN, Reinhard. Socialización y educación política de la niñez y adolescencia en la RFA y en los Estados Unidos en Varios autores Niñez y democracia. Bogotá,UNICEF/Ariel, 1997.

GARCÍA, Gual Carlos. Introducción a la Mitología Griega, D.F., Alianza Editorial, 2005.

GIDDENS, Anthony. Consecuencias de la modernidad. Madrid, Alianza Universidad, 1997.

GIROLA, Lidia. Representaciones e imaginarios sociales. Tendencias recientes en la investigación en de la Garza Toledo, Enrique y Gustavo Leyva (Eds.) Tratado de metodología de las ciencias sociales: perspectivas actuales. D.F., FCE/UAM, 2012.

GLOCKNER, Julio. Los Volcanes Sagrados. Mitos y rituales en el Popocatépetl y la Iztaccíhuatl. D.F., Punto de lectura, 2012.

GREENSTEIN, Fred I, Socialización política. Socialización en Enciclopedia Internacional de las Ciencias Sociales, vol 10, Bilbao, Aguilar, 1977.

HALBWACHS, Maurice. Los marcos sociales de la memoria. Barcelona, Anthopos, 2004.

HERNÁNDEZ CASTILLO, Rosalva Aída y Navaz, Liliana Suárez. Descolonizando el feminismo: teorías y prácticas desde los márgenes. llinois, Northwestern University, 2008.

HOBSBAWM, Eric y RANGER, Terence (Eds.) The invention of tradition, Cambridge, Cambridge University Press, 1987.

IBÁÑEZ GRACIA, Tomás. "Representaciones sociales teoría y método" en Ibáñez Gracia, Tomás (Coord.) Ideologías de la vida cotidiana. Barcelona, Sendai, 1988. 
IWANISZEWSKI, Stanislaw. "Y las montañas tienen género. Apuntes para el análisis de los sitios rituales de la Iztaccihuatl y el Popocatepetl" en Johanna Broda, Satanislaw Iwaniszewski y Arturo Montero (Coords.) La montaña en el paisaje ritual. D.F., UNAM-IIH/ENAH-INAH/CONACULTA, 2001.

KING, Pablo. El nombre del Popocatépetl, Religión Popular y paisaje ritual en la Sierra Nevada. Veracruz, Editora del Gobierno del Estado de Veracruz, 2010.

LOERA CHÁVEZ Y PENICHE, Margarita y AGUIRRE, Ricardo Cabrera Moradas de Tláloc. Arqueología, historia y etnografía sobre la montaña. D.F., INAH-ENAH-DEH/CONACULTA, 2011.

LÓPEZ LÓPEZ, Alejandro y Chávez, Margarita Loera Amaquemecan. Hacia el despertar de nuestra identidad. D.F., H. Ayuntamiento 1994-1996, 1996.

LÓPEZ LÓPEZ, Horacio Alejandro. Amecameca. Monografía Municipal. Amecameca, Instituto Mexiquense de Cultura/AMECROM, 1999.

MIRCEA, Eliade. El mito del eterno retorno. París, Emecé, 2001.

MONTERO GARCÍA, Arturo. Matlalcueye. El volcán del alma tlaxcalteca. Tlaxcala, Ipan tepeme ihuan oztome, 2012.

MOSCOVICl, Sergei. El psicoanálisis, su imagen y su público. Buenos Aires, Huemul, 1979.

JODELET, Denise. La representación social: fenómenos, concepto y teoría en Moscovici, Serge Psicología social II. D.F., Paidós, 2008.

PIAGET, Jean. Seis estudios de psicología. D.F., Labor S.A. 1986.

ROMERO QUIROZ, Javier. Amaquemecan, Amecameca. D.F., Gobierno del Estado de México, 1975.

SARTORI, Giovanni. Homo Videns: La Sociedad Teledirigida. D.F., Punto De Lectura, 2006.

SECRETARÍA DE DESARROLLO Y VIVIENDA. Plan Municipal de Desarrollo Urbano de Amecameca. Julio 2003. Gobierno del Estado, 2003.

SIRI PODESTÁ, Rossana. Nuestros pueblos hoy y siempre. El mundo de las niñas y los niños nahuas de México a través de sus propias letras y dibujos. Puebla, BUAP, 2002.

VAN DIJK, Teun. (2000). Ideología. Barcelona, Gedisa.

VERA CASTILLO, María Guadalupe. Amecameca. Monografía Municipal. Amecamenca, H.Ayuntamiento Amecameca 1997-2000, 2000.

VILLORO, Luis. Estado Plural, pluralidad de culturas. D.F., UNAM/Paidós, 1998. 


\section{ANEXOS: ESCUELAS Y CUADROS MUESTRA}

Nombre y ubicación de las instituciones educativas encuestadas

\section{PÚBLICA}
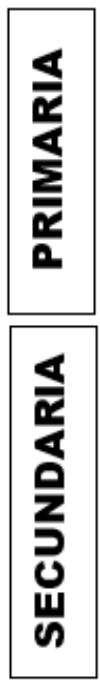
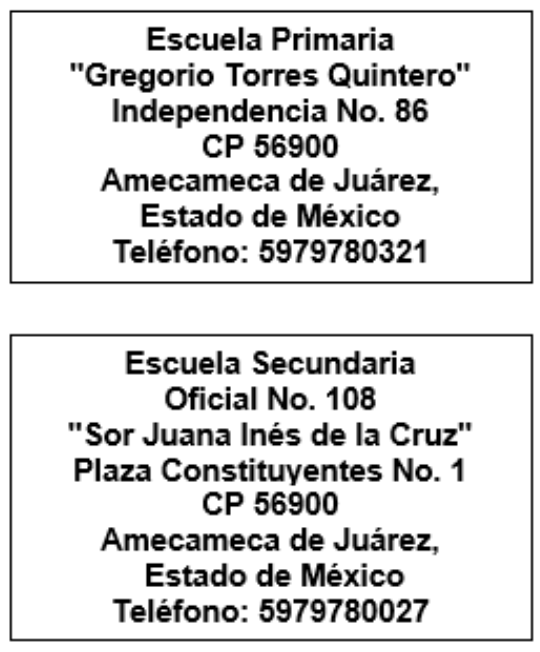

\section{PRIVADA}

Escuela Primaria Instituto Cumbres

Calle Cruz Verde S/N, Sección Sacromonte CP: 56900

Amecameca de Juárez, Estado de México Teléfono: $\mathbf{5 9 7 9 7 8 1 0 2 0}$

Escuela Primaria Niños Héroes,

Calle de la Rosa S/N, CP: 56900

Amecameca de Juárez, Estado de México Teléfono: $\mathbf{5 9 7 9 7 8 2 9 9 0}$

Escuela Secundaria Instituto Cumbres

Calle Cruz Verde S/N, Sección Sacromonte CP: 56900

Amecameca de Juárez, Estado de México Teléfono: $\mathbf{5 9 7 9 7 8 1 0 2 0}$

\section{Escuela Secundaria Niños Héroes,}

Calle de la Rosa S/N, CP: 56900

Amecameca de Juárez, Estado de México Teléfono: $\mathbf{5 9 7 9 7 8 2 9 9 0}$

Los cuestionarios fueron realizados en los meses de marzo y abril del 2013. Para completar la muestra, fue necesario aplicar las encuestas a dos escuelas privadas, debido a que los grupos que manejan las escuelas privadas en Amecameca son grupos reducidos.

Trabalho enviado em 14 de abril de 2017.

Aceito em 25 de abril de 2017. 